\title{
Lack of quadruple and quintuple mutant alleles associated with sulfadoxine-pyrimethamine resistance in Plasmodium vivax isolates from Brazilian endemic areas
}

\author{
Larissa Rodrigues Gomes ${ }^{1,2}$, Aline Lavigne ${ }^{1,2}$, Patrícia Brasil ${ }^{2,4}$, Cassio Leonel Peterka ${ }^{3}$, \\ Didier Ménard ${ }^{5}$, Cláudio Tadeu Daniel-Ribeiro ${ }^{1,2}$, Maria de Fátima Ferreira-da-Cruz, ${ }^{1 /+}$ \\ ${ }^{1}$ Fundação Oswaldo Cruz-Fiocruz, Instituto Oswaldo Cruz, Laboratório de Pesquisa em Malária, Rio de Janeiro, RJ, Brasil \\ ${ }^{2}$ Fundação Oswaldo Cruz-Fiocruz, Centro de Pesquisa, Diagnóstico e Treinamento em Malária, Rio de Janeiro, RJ, Brasil \\ ${ }^{3}$ Ministério da Saúde, Secretaria de Vigilância em Saúde, Programa Nacional de Prevenção e Controle da Malária, Brasília, DF, Brasil \\ ${ }^{4}$ Fundação Oswaldo Cruz-Fiocruz, Instituto Nacional de Infectologia Evandro Chagas, Laboratório de Doenças Febris Agudas, \\ Rio de Janeiro, RJ, Brasil \\ ${ }^{5}$ Institut Pasteur, Malaria Genetic and Resistance Group, Biology of Host-Parasite Interactions Unit, Paris, France
}

BACKGROUND AND OBJECTIVE Brazil is responsible for a large number of Plasmodium vivax cases in America. Given the emergence of $P$. vivax parasites resistant to chloroquine and the effectiveness of antifolates in vivax malaria treatment together with a correlation between mutations in $P$. vivax dhfr and dhps genes and SP treatment failure, the point mutations in these genes were investigated.

METHODS Blood samples from 54 patients experiencing vivax malaria symptomatic episodes in the Amazonian Region were investigated. Genomic DNA was extracted using a DNA extraction kit (QIAGEN ${ }^{\mathrm{TM}}$ ). Nested polymerase chain reaction (PCR) amplification was carried out followed by Sanger sequencing to detect single nucleotide polymorphisms (SNPs).

FINDINGS All tested isolates showed non-synonymous mutations in pvdhfr gene: $117 \mathbf{N}(54 / 54,100 \%)$ and 58R (25/54, 46\%).

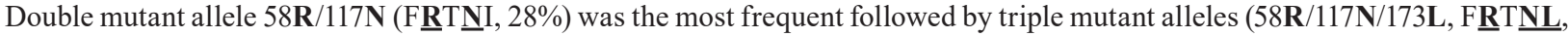

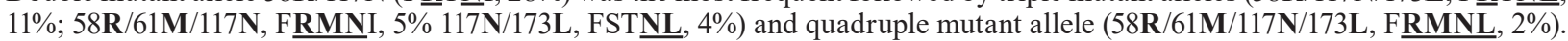
A single mutation was observed at codon C383G in $p v d h p s$ gene (S $\underline{G}$ AV, 48\%).

CONCLUSION No evidence of molecular signatures associated with $P$. vivax resistance to SP was observed in the Brazilian samples.

Key words: P. vivax - malaria - pvdhfr - pvdhps - chemoresistance

Plasmodium vivax is the most geographically widespread human malaria parasite. It is prevalent mainly outside Africa including Asia, South and Central America, and the Middle East. In the Americas, the burden of vivax malaria mostly affects Venezuela and Brazil. In Brazil, malaria transmission occurs almost entirely (>99\% of the registered cases) within the northern Brazilian Amazon Region where both P. falciparum and $P$. vivax infections co-exist. In this area, $P$. vivax is the predominant species, responsible for $89 \%$ of 194,409 malaria cases reported in 2017.(1) Nowadays, falciparum malaria is treated with a 3-day fixed Artesunate+Mefloquine combination, according to Brazilian National Malaria Program guidelines, and a radical cure for P. vivax malaria is achieved with $25 \mathrm{mg} / \mathrm{kg}$ of CQ base for three days (maximum adult dose, $1.5 \mathrm{~g}$ for three days), com-

doi: 10.1590/0074-02760180425

Financial support: POM (Fiocruz), PNCM, Secretaria de Vigilância em Saúde, Ministério da Saúde.

CTDR and MFFC are recipients of a Research Productivity Fellowship from the CNPQ and FAPERJ as Cientistas do Nosso Estado. LRG received a doctoral fellowship from FAPERJ.

+ Corresponding author: mffcruz@ioc.fiocruz.br

(1D http://orcid.org/0000-0003-3522-3792

Received 4 September 2018

Accepted 26 December 2018 bined with a short hypnozoitocidal regimen of $0.5 \mathrm{mg} /$ $\mathrm{kg} /$ day of primaquine $(\mathrm{PQ}$ ) base (maximum daily dose, $30 \mathrm{mg} /$ day) for seven days in patients that weighed below $70 \mathrm{~kg}$. As subtherapeutic PQ doses may lead to relapse in overweight patients, weight-adjusted PQ doses are now recommended in Brazil for patients over $70 \mathrm{~kg}$.

$P$. falciparum resistance to chloroquine (CQ) observed in the 1980s greatly contributed to the emergence of falciparum malaria outbreaks across Amazon.(2) $P$. vivax resistance to CQ occurred later in 1989 in Papua New Guinea ${ }^{(3)}$ and CQ monotherapy was ineffective. Following this seminal observation, numerous cases of $\mathrm{CQ}$ resistance were reported in Southeast Asia ${ }^{(4)}$ and South America, ${ }^{(5,6)}$ thus complicating the current international efforts for malaria control and elimination, and signalling the need for alternative drugs for vivax malaria treatment.

Antifolates, most notably sulfadoxine-pyrimethamine (SP), have been used as anti-malaria for P. falciparum treatment throughout the world because this combination is inexpensive, relatively safe, and requires only a single dose course treatment. SP had been available in Brazil since 1960s to treat CQ-resistant falciparum malaria but SP-resistant $P$. falciparum isolates appeared since 1990; SP is not used for malaria therapy in Brazil. Although resistant to antifolates, P. falciparum treatment has been well documented in many parts of the world, and $P$. vivax chemoresistance to $\mathrm{SP}$ is scarcely studied. 
Sulfadoxine and pyrimethamine are competitive inhibitors of dihydropteroate synthase (dhps) and dihydrofolate reductase ( $(h f r)$, the two major proteins involved in folate biosynthesis pathway ${ }^{(7)}$. Polymorphisms in these two genes are the major factors associated with SP resistance.

Data on $p v d h f r$ and $p v d h p s$ genotypes are available for many Southeast Asian countries. Such reports remain limited for some $P$. vivax endemic areas, notably South America. In Brazil, only one study characterising polymorphisms in $p v d h f r$ gene was documented ${ }^{8)}$ and there is no report on the frequency of single nucleotide polymorphism (SNP) in dhps gene in $P$. vivax clinical isolates from Brazilian endemic areas.

Given the emergence of $P$. vivax CQ resistant parasites and the effectiveness of antifolates in malaria vivax treatment together with a strong correlation between mutations in P. vivax dhfr and dhps genes and SP treatment failure, ${ }^{(9)}$ the present paper reports an investigation on the pattern of point mutations in pvdhfr and pvdhps genes in Brazilian isolates.

\section{MATERIALS AND METHODS}

Parasites isolates and DNA extraction - Blood samples from Amazon Region (Acre, Amapá, Amazonas, Rondônia and Pará) were collected from 54 patients presenting with vivax malaria from 2010 to 2016 at the Laboratório de Doenças Febris Agudas, INI-IPEC, Fiocruz, the Reference Clinical Laboratory for Malaria in the ExtraAmazon to the Brazilian Ministry of Health. All the clinical isolates were diagnosed as single $P$. vivax infections by light microscopic examination of Giemsa's solutionstained blood smears and by $P$. vivax cysteine-proteinase target gene polymerase chain reaction (PCR). ${ }^{(10)}$ The parasitaemia ranged from 960 to 19160 parasites/ $\mu \mathrm{L}$. All malaria patients presented with clinical signs and/or symptoms of uncomplicated malaria, such as fever, headache, and chills, and the baseline characteristics were similar. No significant difference in parasitaemia was observed among the studied Brazilian localities and all the Brazilian endemic states were hypoendemic malaria areas.

Genomic DNA was extracted using a commercially available DNA extraction kit (QIAGEN ${ }^{\mathrm{TM}}$, Frankfurt, Germany), following the manufacturer's instructions. This study was performed according to the protocols previously approved by the Ethical Research Committees of Fiocruz (32839013.6.00005248). Patients were treated with CQ plus $\mathrm{PQ}$, according to the Brazilian Ministry of Health recommendation for uncomplicated vivax malaria treatment and were followed up to 42 days. No treatment failure was detected during this period.

Nested PCR and electrophoresis - Nested PCR amplification of $p v d h f r$ and pvdhps were carried out as described previously. ${ }^{(11)}$ Ten point mutations were investigated: F57L/I, S58R, T61M, S117T/N and I173F/L for $p v d h f r$, and S382A, C383G, K512M/T/E, A553G and V585G for $p v d h p s$. PCR products were analysed by ethidium bromide-stained agarose-gel (2\%) electrophoresis.

DNA sequencing and SNPs detection - The $632 \mathrm{bp}$ and $767 \mathrm{bp}$ fragments generated by amplification of $p v d h f r$ and $p v d h p s$, respectively, were extracted and purified from gel using the Wizard ${ }^{\circledR}$ SV Gel and PCR Clean-Up System (Promega, Madison, WI, USA) commercial kits. Briefly, the amplified fragments were sequenced using BigDye Terminator cycle sequencing ready reaction version 3.1 and ABI Prism DNA analyser 3730 (Applied Biosystems) at the Genomic Platform/PDTIS/Fiocruz. The direct DNA sequencing from PCR products were compared with the reference Sal I sequence of $p v d h f r$ (GenBank X98123) and pvdhps (GenBank AY186730.1). Forward and reverse sequences were analysed using the free software, Bioedit Sequence Alignment Editor version 7.2.5. PCRs and DNA sequencing were randomly repeated to check possible sequence errors introduced during these stages.

\section{RESULTS}

All the 54 isolates sequenced for $p v d h f r$ gene showed non-synonymous mutations: $117 \mathbf{N}(54 / 54 ; 100 \%)$ and $58 \mathbf{R}(25 / 54 ; 46 \%)$ mutant alleles were more frequent, while $173 \mathbf{L}(9 / 54 ; 17 \%)$ and $61 \mathbf{M}(4 / 54 ; 7 \%)$ were detected at lower frequencies. Mutation at position $57 \mathbf{L}$ was not found (Table I). The most common single mutant allele was $117 \mathbf{N}(27 / 54 ; 50 \%)$. This single mutant was more frequent in Acre (10/15; 66\%), Amazonas (11/23; $52 \%$ ) and Pará states $(4 / 8 ; 50 \%)$, compared to Rondônia state $(1 / 7 ; 14 \%)$, where double $58 \mathbf{R}+117 \mathbf{N}$ mutant was dominant (Table II). Independent of the year collection, Amazonas state showed the highest number of $p v d h f r$ gene mutations $(23 / 54 ; 42,5 \%)$, followed by Acre $(15 / 54$; $27,7 \%$, Para $(8 / 54 ; 15 \%)$ and Rondônia $(7 / 54,13 \%)$ (Tables III-VI). Apparently in 2011, Acre presented more pvdhfr gene mutations $(7 / 15 ; 47 \%)$ than Amazonas $(2 / 23$; $8,6 \%$ ) (Tables III-IV), but this difference could be related to the smaller number of Amazonas samples collected in 2011, because when percentages are compared instead of figures, $100 \%$ of Amazonas (2/2) and Acre samples (7/7) presented mutations in 2011.

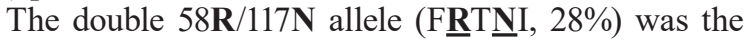
most common allele, contrasting with the frequencies of other $d h f r$ double, triple, or quadruple mutant alleles, with lower frequencies: 58R/117N/173L (FRTNL, 11\%), 58R/61 M/117N (FRMNI, 5\%), 117N/173L (FST $\underline{\text { NL }, 4 \%), ~}$ and $58 \mathbf{R} / 61 \mathbf{M} / 117 \mathbf{N} / 173 \mathbf{L}$ (FRMNL, 2\%). In all localities, wild-type pvdhfr (FSTSI) was not observed (Table VII). The $58 \mathbf{R} / 117 \mathbf{N}$ double mutant allele was detected in Acre (2/15; 13\%), Rondônia (5/7; 71\%), and Amazonas (8/23;

\section{TABLE I}

Plasmodium vivax dhfr and dhps amino acid changes in 54 P. vivax isolates from Brazilian endemic areas

\begin{tabular}{lcc}
\hline Gene & SNPs & Prevalence N (\%) \\
\hline$d h f r$ & $58 \mathbf{R}$ & $25(46)$ \\
& $61 \mathbf{M}$ & $4(7)$ \\
& $117 \mathbf{N}$ & $54(100)$ \\
& $173 \mathbf{L}$ & $9(17)$ \\
dhps & $383 \mathbf{G}$ & $26(48)$ \\
\hline
\end{tabular}

SNPs: single nucleotide polymorphisms. 
TABLE II

Number of alleles in dhfr and dhps genes observed among 54 Brazilian Plasmodium vivax isolates, according to sampling location

\begin{tabular}{ccccccc}
\hline Gene & SNPs & $\begin{array}{c}\text { Amazonas } \\
(\mathrm{n}=23)\end{array}$ & $\begin{array}{c}\text { Acre } \\
(\mathrm{n}=15)\end{array}$ & $\begin{array}{c}\text { Amapá } \\
(\mathrm{n}=1)\end{array}$ & $\begin{array}{c}\text { Pará } \\
(\mathrm{n}=8)\end{array}$ & $\begin{array}{c}\text { Rondônia } \\
(\mathrm{n}=7)\end{array}$ \\
\hline$d h f r$ & $117 \mathbf{N}$ & 12 & 10 & - & 4 & 1 \\
& $58 \mathbf{R} / 117 \mathbf{N}$ & 8 & 2 & - & - & 5 \\
& $117 \mathbf{N} / 173 \mathbf{L}$ & - & - & 1 & 1 & - \\
& $58 \mathbf{R} / 117 \mathbf{N} / 173 \mathbf{L}$ & 1 & 3 & - & - & - \\
& $58 \mathbf{R} / 61 \mathbf{M} / 117 \mathbf{N}$ & 1 & - & - & - & - \\
dhps & $58 \mathbf{R} / 61 \mathbf{M} / 117 \mathbf{N} / 173 \mathbf{L}$ & 1 & - & - & 5 & - \\
\hline
\end{tabular}

SNPs: single nucleotide polymorphisms.

TABLE III

Number of alleles in dhfr and dhps genes observed among 23 Plasmodium vivax isolates from Amazônia, according to year of blood collection

\begin{tabular}{|c|c|c|c|c|c|c|c|c|}
\hline Genotype & Mutation codon & 2010 & 2011 & 2012 & 2013 & 2015 & 2016 & Total \\
\hline \multirow[t]{6}{*}{ Dhfr } & $117 \mathbf{N}$ & 5 & - & 1 & - & 4 & 2 & 12 \\
\hline & $58 \mathbf{R} / 117 \mathbf{N}$ & 1 & 2 & 1 & - & 3 & 1 & 8 \\
\hline & $58 \mathbf{R} / 117 \mathbf{N} / 173 \mathbf{L}$ & - & - & - & 1 & - & - & 1 \\
\hline & $58 \mathbf{R} / 61 \mathbf{M} / 117 \mathbf{N}$ & - & - & 1 & - & - & - & 1 \\
\hline & $58 \mathbf{R} / 61 \mathbf{M} / 117 \mathbf{N} / 173 \mathbf{L}$ & - & - & 1 & - & - & - & 1 \\
\hline & TOTAL & 6 & 2 & 4 & 1 & 7 & 3 & 23 \\
\hline Dhps & $383 \mathbf{G}$ & 5 & - & 4 & 1 & 2 & 1 & 13 \\
\hline
\end{tabular}

$35 \%$ ) while the $117 \mathbf{N}+173 \mathbf{L}$ only in Pará and Rondônia. The triple mutant allele 58R/117N/173L was found in all localities, except Rondônia, and the quadruple mutant $58 \mathbf{R} / 61 \mathbf{M} / 117 \mathbf{N} / 173 \mathbf{L}$ was observed only in one isolate collected from Amazonas state $(1 / 23 ; 4 \%$ ) (Table VIII). The frequencies of double, triple, or quadruple mutants were not related to the year of collection (Tables III-VI).

Concerning pvdhps gene in 26 out of 54 (48\%) isolates only a single mutation at codon $\mathrm{C} 383 \mathbf{G}$ was detected. No other mutations, including $382 \mathrm{~A}, 512 \mathbf{M}, 553 \mathbf{G}$, and $585 \mathrm{C}$, were found. The wild-type SCKAV (52\%) and single haplotype SGKAV (48\%) were observed at similar frequencies. The single mutant $383 \mathbf{G}$ was observed in isolates from Amazonas (13/23, 56\%), Acre $(8 / 15,53 \%)$ and Pará $(5 / 8,62 \%)$ but not in isolates from Rondônia state $(0 / 7)$ (Table II). Once again frequencies of $p v d h p s$ gene mutations were not related to the year of collection (Tables III-VI).

Combining $p v d h f r$ and $p v d h p s$ alleles, only one haplo-

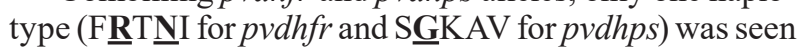
in three of the four study sites with a higher frequency in Amazonas state (where one $p v d h f r$ quadruple mutant was detected) (Table IX). No pvdhfr or pvdhps quadruple or quintuple mutant haplotype, which might result in poor clinical response against antifolate drugs, was detected in any of the Brazilian localities investigated.

\section{DISCUSSION}

Mutations in pvdhfr and pvdhps genes have been found to be associated with antifolate drug resistance. Both in vivo ${ }^{(13)}$ and in vitro assays suggested that these molecular markers may provide information about the trends of SP resistance in $P$. vivax. Here, we investigated SP resistance in vivax isolates by seeking specific point mutations in $p v d h f r$ and $p v d h p s$ genes.

It has been postulated that $p v d h f r \quad 117 \mathbf{N}$ mutation might occur first, followed by S58R mutation. ${ }^{(14)}$ In this study, $p v d h f r$ S117N was detected in all isolates followed by $58 \mathbf{R}(74 \%), 173 \mathbf{L}(17 \%)$, and $61 \mathbf{M}(7 \%)$ polymorphisms, supporting that S117N mutation is the first step in drug selection process. These data are similar to other observations done in areas where $P$. falciparum and $P$. vivax parasites co-exist. ${ }^{(14,15)}$

The predominance of S117N followed by the double mutant $58 \mathbf{R} / 117 \mathbf{N}(28 \%)$ was also analogous to those reported in India, ${ }^{(15)}$ Afghanistan, ${ }^{(16)}$ China, ${ }^{(17)}$ Nepal, ${ }^{(18)}$ Thailand, ${ }^{(19)}$ Colombia, ${ }^{(20,21)}$ French Guiana $^{(19)}$ and Brazil. (8) The triple $58 \mathbf{R} / 117 \mathbf{N} / 173 \mathbf{L}$ pvdhfr mutant, not seen in $P$. vivax samples from Southeast Asian, where non-synonymous mutation in codon 173 comprises the change of I by F generating the $173 \mathbf{F}$ allele, was here detected in Amazonas, Acre, Amapá and Pará states and also in $P$. vivax parasites from French Guiana ${ }^{(19,22)}$ and Amazonas, 
TABLE IV

Number of alleles in $d h f r$ and dhps genes observed among 15 Plasmodium vivax isolates from Acre, according to year of blood collection

\begin{tabular}{lccccccc}
\hline Genotype & Mutation codon & 2011 & 2013 & 2014 & 2015 & 2016 & Total \\
\hline Dhfr & $117 \mathbf{N}$ & 4 & - & - & 4 & 2 & 10 \\
& $58 \mathbf{R} / 117 \mathbf{N}$ & 1 & - & 1 & - & - & 3 \\
& $58 \mathbf{R} / 117 \mathbf{N} / 173 \mathbf{L}$ & 2 & 1 & - & - & 2 & 15 \\
\cline { 2 - 5 } & TOTAL & 7 & 1 & - & 2 & 1 \\
\hline
\end{tabular}

TABLE V

Number of alleles in $d h f r$ and dhps genes observed among eight Plasmodium vivax isolates from Pará, according to year of blood collection

\begin{tabular}{lccccccc}
\hline Genotype & Mutation codon & 2010 & 2011 & 2013 & 2015 & 2016 & Total \\
\hline Dhfr & $117 \mathbf{N}$ & 1 & - & - & 1 & 2 & 4 \\
& $117 \mathbf{N} / 173 \mathbf{L}$ & - & 1 & - & - & - & 1 \\
& $58 \mathbf{R} / 117 \mathbf{N} / 173 \mathbf{L}$ & - & - & 1 & - & - & 2 \\
& $58 \mathbf{R} / 61 \mathbf{M} / 117 \mathbf{N}$ & - & - & - & 1 & 2 & 8 \\
\cline { 2 - 6 } & TOTAL & $\mathbf{1}$ & $\mathbf{1}$ & - & 1 & 2 & 5 \\
\hline
\end{tabular}

Brazil. ${ }^{(8)}$ Conversely, the non-synonymous mutation at position F57L not recorded in this study was exclusively reported in Southeast Asian samples; findings that could reflect different drug pressure history and selective processes in the old and new worlds. In fact, the genetic similarity of $173 \mathrm{~L}$ SNP recorded for $P$. vivax parasites from two neighbouring South-American countries Brazil and French Guiana, ${ }^{(19)}$ reinforce the possible existence of geographic subdivision of different $P$. vivax parasites in samples from the old and new worlds.

Concerning the $p v d h p s$ gene, previous data indicated that mutations were mainly detected at codons A383G and $A 553 \mathbf{G}^{(14,21,23,24)}$ and suggested that these mutations alone could be responsible for reduced sensitivity to sulfa and sulfones. ${ }^{(25,26)}$ In the present work, the wild-type $(52 \%)$ and the mutated codon $383 \mathrm{G}$ (48\%) were detected at similar frequencies among $P$. vivax isolates, similar to reports from Thai-Cambodian $(53 \%){ }^{(7)}$ Thai-Myanmar border $(47 \%)^{(27)}$ and Indonesia $(50 \%) .{ }^{(9)}$ Whereas, in a Colombian study investigating polymorphisms in pvdhps, the wild-type was the most frequently detected $(71.6 \%){ }^{(21)}$ the same was true in India $(79 \%)^{(15)}$ and also in Thai - Cambodian border $(74 \%) .{ }^{(28)}$ Therefore, the pvdhps wild-type allele seems to be common in malaria endemic areas of the world, probably due to a low SP drug selection in the sympatric $P$. vivax populations of these countries. However, in Brazil, for example, SP or its analogues have been used for fever and antimicrobial therapy and, in this way, there continues to be a lengthy selection pressure for SP-resistant strains of $P$. vivax resulting to low frequencies of wild-type $p v d h p s$ parasites.

Amazonas state recorded the highest number of $p v d-$ $h f r$ and pvdhps mutations. This finding could not be attributed to differences of antimalarial drug usage in Brazilian states because the malaria treatment in Brazil is the same all over the country. Besides that, SP has never been recommended for vivax malaria treatment and SP has been excluded from $P$. falciparum treatment since 1989. Thus, it is more reasonable suppose that more mutations were found in Amazonas due to the highest number of samples examined from this locality, as only one sample from Amazonas was from a border area of the Amazon

\section{TABLE VI}

Number of alleles in $d h f r$ gene observed among seven Plasmodium vivax isolates from Rondônia, according to year of blood collection

\begin{tabular}{cccccc}
\hline Genotype & Mutation codon & 2010 & 2011 & 2014 & Total \\
\hline \multirow{4}{*}{ Dhfr } & $117 \mathbf{N}$ & 1 & - & - & 1 \\
& $58 \mathbf{R} / 117 \mathbf{N}$ & - & 2 & 3 & 5 \\
& $117 \mathbf{N} / 173 \mathbf{L}$ & - & - & 1 & 1 \\
\cline { 2 - 6 } & TOTAL & $\mathbf{1}$ & $\mathbf{2}$ & 4 & 7 \\
\hline
\end{tabular}


TABLE VII

Deduced $d h f r$ and dhps haplotype profiles in 54 Plasmodium vivax isolates from Brazilian endemic areas

\begin{tabular}{lccc}
\hline Gene & Haplotypes & N & $\%$ \\
\hline$d h f r$ & FSTNI & 27 & 50 \\
& FRTNI & 15 & 28 \\
& FSTNL & 2 & 4 \\
& FRTNL & 6 & 11 \\
& FRMNI & 3 & 5 \\
& FRMNL & 1 & 2 \\
dhps & SGKAV & 26 & 48 \\
& SCKAA (wild type) & 28 & 52
\end{tabular}

Bold letters: mutated codons; F: codon 57; S: codon 58; T: codon 61; S: codon 117; I: codon 173.

\section{TABLE VIII}

Prevalence of Plasmodium vivax dhfr and dhps amino acid changes in 54 P. vivax isolates from Brazilian endemic areas

\begin{tabular}{cccc}
\hline Gene & Mutants & SNPs & $\begin{array}{c}\text { Prevalence } \\
\text { N (\%) }\end{array}$ \\
\hline$d h f r$ & Single & S117N & $27(50)$ \\
& Double & S58R/S117N & $15(28)$ \\
& & S117N/ I173L & $2(4)$ \\
& Triple & S58R/S117N/I173L & $6(11)$ \\
& & S58R/T61M/S117N & $3(5)$ \\
& Quadruple & S58R/T61M/S117N/ I173L & $1(2)$ \\
dhps & Single & C383G & $26(48)$ \\
\hline
\end{tabular}

SNP: single nucleotide polymorphisms.

with Acre - the second state that showed the greatest number of mutations. A study with a representative number of Amazonian state cases may help answer this question.

In conclusion, we found no molecular strong evidence of $P$. vivax SP resistance in recently collected Brazilian samples. As mutations in $P$. vivax dhps and $d h f r$ genes provide a valuable tool for epidemiological surveillance of SP resistance, the prevalence of point mutations on these genetic markers of SP resistance should be assessed for providing information for future treatment policy with alternative antifolate drugs because of the appearance and dispersion of CQ resistance in malaria endemic areas.

\section{AUTHORS' CONTRIBUTION}

MFFC idealide the study, participate in the discussion and review the manuscript; LRG performed PCRs, analysis DNA sequencing and drafted the manuscript; CTDR, CLP and DM participated in the discussions and reviewed the final manuscript; AL performed DNA extraction and molecular diagnosis; PB recruited the patients. All authors read and approved the final manuscript.
TABLE IX

Percentage of double mutant $d h f r$ / single mutant dhps in 54 Plasmodium vivax samples according to Brazilian states

\begin{tabular}{lcc}
\hline Amazônia & Acre & Pará \\
\hline NP (\%) & NP (\%) & NP (\%) \\
\hline $13(24)$ & $8(15)$ & $5(9)$ \\
\hline
\end{tabular}

NP: number of positive.

\section{REFERENCES}

1. SVS - Secretaria de Vigilância em Saúde. 2018. Available from: http://portalms.saude.gov.br/svs.

2. Gama BE, Lacerda MVG, Daniel-Ribeiro CT, Ferreira-da-Cruz MF. Chemoresistance of Plasmodium falciparum and Plasmodium vivax parasites in Brazil: consequences on disease morbidity and control. Mem Inst Oswaldo Cruz. 2011; 106(Suppl. 1): 159-66.

3. Rieckmann KH, Davis DR, Hulton DC. Plasmodium vivax resistance to chloroquine? Lancet. 1989; 18(2): 1183-4.

4. Thanh PV, Hong NV, Van NV, Louisa M, Baird K, Xa NX, et al. Confirmed Plasmodium vivax resistance to Chloroquine in Central Vietnam. Antimicrob Agents Chemother. 2015; 59(12): 7411-9.

5. Soto J, Toledo J, Gutierrez P, Luzz M, Llinas N, Cedeno N, et al. Plasmodium vivax clinically resistant to chloroquine in Colombia. Am J Trop Med Hyg. 2001; 65(2): 90-3.

6. de Santana Filho FS, Arcanjo AR, Chehuan YM, Costa MR, Martinez-Espinosa FE, Vieira JL, et al. Chloroquine-resistant Plasmodium vivax, Brazilian Amazon. Emerg Infect Dis. 2007; 13(7): 1125-6.

7. Tantiamornkul K, Pumpaibool T, Piriyapongsa J, Culleton R, LekUthai U. The prevalence of molecular markers of drug resistance in Plasmodium vivax from the border regions of Thailand in 2008 and 2014. Int J Parasitol Drugs Drug Resist. 2018; 8(2): 229-37.

8. Gama BE, Oliveira NK, Souza JM, Daniel-Ribeiro CT, Ferreirada-Cruz MF. Characterisation of $p v m d r 1$ and $p v d h f r$ genes associated with chemoresistance in Brazilian Plasmodium vivax isolates. Mem Inst Oswaldo Cruz. 2009; 104(7): 1009-11.

9. Asih PB, Marantina SS, Nababan R, Lobo NF, Rozi IE, Sumarto W, et al. Distribution of Plasmodium vivax pvdhfr and pvdhps alleles and their association with sulfadoxine-pyrimethamine treatment outcomes in Indonesia. Malar J. 2015; 14: 365-71.

10. Torres KL, Figueiredo DV, Zalis MG, Daniel-Ribeiro CT, Alecrim W, Ferreira-da-Cruz MF. Standardization of a very specific and sensitive single PCR for detection of Plasmodium vivax in low parasitized individuals and its usefulness for screening blood donors. Parasitol Res. 2006; 98(6): 519-24.

11. Mint Lekweiry K, Boukhary AOMS, Gaillard T, Wurtz N, Bogreau $\mathrm{H}$, Hafid JE, et al. Molecular surveillance of drug-resistant Plasmodium vivax using $p v d h f r, p v d h p s$ and $p v m d r 1$ markers in Nouakchott, Mauritania. J Antimicrob Chemother. 2012; 67(2): 367-74.

12. Otto TD, Vasconcellos EA, Gomes LH, Moreira AS, Degrave WM, Mendonça-Lima L, et al. ChromaPipe: a pipeline for analysis, quality control and management for a DNA sequencing facility. Genet Mol Res. 2008; 7(3): 861-71.

13. Marfurt J, de Monbrison F, Brega S, Barbollat L, Müller I, Sie A, et al. Molecular markers of in vivo Plasmodium vivax resistance to amodiaquine plus sulfadoxine-pyrimethamine: mutations in $p v d$ hfr and pvmdrl. J Infect Dis. 2008; 198(3): 409-17. 
14. Das S, Banik A, Hati AK, Roy S. Low prevalence of dihydrofolate reductase (dhfr) and dihydropteroate synthase (dhps) quadruple and quintuple mutant alleles associated with SP resistance in Plasmodium vivax isolates of West Bengal, India. Malar J. 2016; 15(1): 395-404.

15. Ganguly S, Saha P, Chatterjee M, Maji AK. Prevalence of polymorphisms in antifolate drug resistance molecular marker genes pvdhfr and pvdhps in clinical isolates of Plasmodium vivax from Kolkata, India. Antimicrob Agents Chemother. 2014; 58(1): 196-200.

16. Zakeri S, Afsharpad M, Ghasemi F, Raeisi A, Safi N, Butt W, et al. Molecular surveillance of Plasmodium vivax dhfr and dhps mutations in isolates from Afghanistan. Malar J. 2010; 9: 75-82.

17. Huang B, Huang S, Su XZ, Tong X, Yan J, Li H, et al. Molecular surveillance of pvdhfr, pvdhps, and pvmdr-1 mutations in Plasmodium vivax isolates from Yunnan and Anhui provinces of China. Malar J. 2014; 13: 346-55.

18. Ranjitkar S, Schousboe ML, Thomsen TT, Adhikari M, Kapel $\mathrm{CM}$, Bygbjerg IC, et al. Prevalence of molecular markers of antimalarial drug resistance in Plasmodium vivax and Plasmodium falciparum in two districts of Nepal. Malar J. 2011; 10: 75-82.

19. Brega S, de Monbrison F, Severini C, Udomsangpetch R, Sutanto I, Ruckert P, et al. Real-time PCR for dihydrofolate reductase gene single-nucleotide polymorphisms in Plasmodium vivax isolates. Antimicrob Agents Chemother. 2004; 48(7): 2581-7.

20. Hawkins VN, Auliff A, Prajapati SK, Rungsihirunrat K, Hapuarachchi HC, Maestre A, et al. Multiple origins of resistance-conferring mutations in Plasmodium vivax dihydrofolate reductase. Malar J. 2008; 7: 72-83.
21. Saralamba N, Nakeesathit S, Mayxay M, Newton PN, Osorio L, Kim JR, et al. Geographic distribution of amino acid mutations in DHFR and DHPS in Plasmodium vivax isolates from Lao PDR, India and Colombia. Malar J. 2016; 15: 484-90.

22. Barnadas C, Musset L, Legrand E, Tichit M, Briolant S, Fusai $\mathrm{T}$, et al. High prevalence and fixation of Plasmodium vivax $\mathrm{dhfr} /$ dhps mutations related to sulfadoxine/pyrimethamine resistance in French Guiana. Am J Trop Med Hyg. 2009; 81(1): 19-22.

23. Prajapati SK, Joshi H, Dev V, Dua VK. Molecular epidemiology of Plasmodium vivax anti-folate resistance in India. Malar J. 2011; 10: $102-8$.

24. Kuesap J, Rungsrihirunrat K, Thongdee P, Ruangweerayut R, NaBangchang $\mathrm{K}$. Change in mutation patterns of Plasmodium vivax dihydrofolate reductase (Pvdhfr) and dihydropteroate synthase (Pvdhps) in P. vivax isolates from malaria endemic areas of Thailand. Mem Inst Oswaldo Cruz. 2011; 106(Suppl. 1): 130-3.

25. Korsinczky M, Fischer K, Chen N, Baker J, Rickmann K, Cheng Q. Sulfadoxine resistance in Plasmodium vivax is associated with a specific amino acid in dihydropteroate synthase at the putative sulfadoxine-binding site. Antimicrob Agents Chemother. 2004; 48(6): $2214-22$

26. Imwong M, Pukrittayakamee S, Cheng Q, Moore C, Looareesuwan S, Snounou G, et al. Limited polymorphism in the dihydropteroate synthetase gene (dhps) of Plasmodium vivax isolates from Thailand. Antimicrob Agents Chemother. 2005; 49(10): 4393-5.

27. Thongdee P, Kuesap J, Rungsihirunrat K, Tippawangkosol P, Mungthin M, Na-Bangchang K. Distribution of dihydrofolate reductase (dhfr) and dihydropteroate synthase (dhps) mutant alleles in Plasmodium vivax isolates from Thailand. Acta Trop. 2013; 128(1): 137-43. 